УДК 111.1

DOI dx.doi.org/10.24866/1997-2857/2018-4/79-82

\title{
И.И. Докучаев*
}

\section{МАРКСИЗМ И ИСТОРИЧЕСКАЯ ТИПОЛОГИЯ КУЛЬТУРЫ}

В статье анализируется возможность использования классического постулата марксизма о базисном характере производельных сил для объяснения культурно-исторической динамики и построения исторической типологии культуры. Основной вывод статьи - указанный постулат хорошо работает для объяснения динамики архаической и традиционной культуры, поскольку в эти периоды именно технический прогресс оказывался инновационной силой, приводящей к смене исторических типов культуры. Однако данный постулат не позволяет объснить содержание этих типов. В отношении же динамики креативной культуры он не позволяет объяснить ни содержание исторических типов, ни их смену. Это объясняется основным свойством марксизма, характерным для науки XIX в. редукционизмом, который не позволил учесть и другие - помимо материальной культуры - факторы, определяющие историческую динамику креативной культуры, - религию, политическую идеологию, науку.

Ключевые слова: К. Маркс, базис, надстройка, традиционная культура, креативная культура, типология культуры

Marxism and historical typology of culture. ILYA I. DOKUCHAEV (Herzen State Pedagogical University of Russia)

The paper focuses on the question of how we can use the classical Marxist thesis of productive forces as a basis for explaining historical cultural dynamics and building historical typology of culture. The key finding and conclusion of the paper is that this postulation of marxism works pretty well for explaining the dynamics of the archaic and traditional types of culture since it was in those periods of social evolution that technological advancement played the role of an innovative driver bringing about the succession of historical types of culture. This theory, however, fails to explain the content of these historical types. As for the creative type of cultural dynamics, it fails to explain both the content of historical types and their succession. This fact can be accounted for the reductionism of Marxism, that did not allow its proponents to take into account other factors (in addition to material culture) decisive for historical dynamics of the creative culture such as religion, political ideology, and science.

Keywords: Karl Marx, basis, superstructure, traditional culture, creative culture, typology of culture

Основным своим вкладом в науку и философию Карл Маркс всегда считал концепцию материалистического понимания истории. Эта концепция была призвана объяснить процесс исторической динамики культуры, изменений в существе того или иного исторического перио-

* ДОКУЧАЕВ Илья Игоревич, доктор философских наук, заведующий кафедрой теории и истории культуры Института философии человека Российского государственного педагогического университета им. А.И. Герцена.

E-mail: ilya_dokuchaev@mail.ru

(С) Докучаев И.И., 2018 
да, а также механизм истории в целом. Кратко эта концепция была сформулирована следующим образом: «В общественном производстве своей жизни люди вступают в определенные, необходимые, от их воли не зависящие отношения - производственные отношения, которые соответствуют определенной ступени развития их материальных производительных сил. Совокупность этих производственных отношений составляет экономическую структуру общества, реальный базис, на котором возвышается юридическая и политическая надстройка и которому соответствуют определенные формы общественного сознания» [4, с. 6-7]. Таким образом, основной динамической силой культуры оказывается совокупность производительных сил, включающих средства производства и самих производителей, то есть материальная культура. Уровень ее развития формирует производственные отношения (базис), а затем и политико-правовые (надстройку первого типа). Независимо от последних производственные отношения формируют общественное сознание, включая научные, художественные и религиозные его составляющие (надстройку второго типа, сохраняющую определенную независимость от базиса и даже имеющую некоторое влияние на него и на производительные силы). Именно к надстроечным формам истории относятся ценности, которые содержатся, прежде всего, в религиозных и политико-правовых формах культуры.

Сегодня эта схема в ее последовательном и жестком варианте представляется формой редукционизма, упрощающего реальное существо исторической динамики. Преодолению этого редукционизма в значительной мере способствовали исследования немецких социологов и философов рубежа XIX-XX вв., таких как Макс Вебер [2] и Генрих Риккерт [5], обративших внимание на существенную роль ценностей в качестве динамической силы истории. Производительные силы с учетом этой коррекции оказываются одной из таких динамических сил, а именно - инновационной, которая корректируется другой силой, а именно - традиционной, связанной с ценностями. Ценности стабилизируют и тормозят эволюцию культуру и общества и научно-технический прогресс. Еще одним существенным дополнением марксистского понимания истории стало открытие в XX в. ключевой роли науки, как в общественном, так и в природном плане бытия (назову здесь концепции постиндустриального общества Дэниела Белла [1] и концепцию ноосферы Владимира Ивановича Вернадского [3]). Наука оказалась сознанием технического прогресса, придавшим ему цель и смысл, а также существенным образом изменившим природные условия бытия человека. В этом контексте марксизм оказывается ценным вкладом в разработку проблем истории культуры только с учетом указанных коррекций. Попробую кратко представить эту сложную картину, учитывающую как марксистский, так и корректирующий его когнитивно-ценностный подход к проблеме эволюции культуры.

Формирование ценностей происходит параллельно их переоценке. Подготовка нового тезауруса вызревает в недрах культуры, а затем определенные внеценностные силы приводят к переоценке ценностей. Таким образом, на культуру оказывают влияние многие типы артефактов. Некоторые изменяют ее содержание, а некоторые его определяют. Назовем те, которые изменяют, движущими или динамическими силами культурогенеза, а те, которые определяют, - порождающими или стабилизирующими силами культурогенеза. Ценности есть порождающие или стабилизирующие силы культурогенеза. А на его динамику оказывают влияние техника и наука. Первая оказывает это влияние всегда, а вторая присоединяется к первой в эпоху креативной культуры.

Теперь еще раз обратим внимание на трансформации важнейшей динамической, движущей силы изменений исторических типов культуры техники. Эта динамика позволит нам представить данные типы наиболее последовательным образом. Будем говорить о технике как совокупности продуктов преобразования природы и его технологий; поэтому, подчеркивая этот глобальный подход к существу преобразования и его продуктов, назовем их исторические варианты вслед за Гордоном Виром Чайльдом [6] - способами хозяйствования. Способы хозяйствования менялись в ответ на внутренние и внешние стимулы их эволюции. Изменения географической среды, изобретения, поиск более эффективных способов хозяйствования и технологических решений по созданию прогрессивной техники все это и есть движущие силы истории. Техника всегда может улучшаться, а наука развиваться, такова их практическая природа. Ценности же улучшены быть не могут, они могут быть только переоценены или отменены.

Архаическая культура основывалась на присваивающем способе хозяйствования, вклю- 
чавшем в свое синкретическое целое три основных технологии присваивания - охоту, собирательство и производство элементарных орудий труда, куда относились также одежда и жилище. Традиционная культура основывалась на производящем хозяйствовании, причем ее варианты были эволюционными следствиями трех отраслей присваивающего хозяйствования. В результате неолитической революции из охоты произошло скотоводство, из собирательства - земледелие, из элементарного производства орудий труда (то есть для себя) - ремесло (то есть производство орудий труда для других, хотя и вручную) и торговля. Скотоводческая культура оказалась тупиковым путем исторической эволюции. А на основе синтеза земледельческой и торгово-ремесленной культур возникла каноническая, рационализированная средневековая культура. Торгово-ремесленная культура древности была первым универсальным кризисом традиционной культуры, который, однако, не привел к возникновению креативной, но существенно повлиял на этот процесс.

Еще земледельческая культура за счет процесса классообразования и неравномерного распределения излишков производства распалась на две субкультуры - официальную и народную. Ценностная структура этих культур, как правило, не различалась, однако в средневековой культуре она оказалась основной для формирования двух самостоятельных субкультур - народной и аристократической. Торгово-ремесленная культура древности стала основой средневековой субкультуры горожан. А рационализация ценностных религиозных структур и поддерживающих их социальных церковных институтов привела к возникновению особой храмово-монастырской субкультуры.

Рационализированный характер средневековой культуры, богатство накопленного в ее условиях опыта привели к необратимому переходу ее в состояние креативной культуры. Этот переход и есть эпоха Возрождения - первая эпоха креативной культуры. Каждая средневековая субкультура переживала своеобразный вариант перехода, но все они были связаны с утверждением новых типов ценностей - человека, рационального познания и творчества, которые пришли на смену ценностям общества, религиозного откровения и традиции. Народная субкультура постепенно вытеснялась и сливалась с городской, переживавшей такой тип перехода назовем его собственно Ренессанс, - который был основным и заключался в художественном и научно-промышленном перевороте, направленном на возникновение новых способов светского отражения бытия и промышленного (на основе механических станков) преобразования природы. Религиозная субкультура переживала переход - Реформацию, заключавшийся в следующем: переживание религиозных ценностей рационализировалось, из общения с Богом исключались посредники в виде Церкви или Священного предания, человек оказывался наедине с Богом, позволяя себе создавать его по своему образу и подобию. Это привело к субъективизации Бога и его полному отрицанию. Реформация привела к уничтожению религиозной субкультуры. Аристократическая субкультура средневековья подверглась наступлению со стороны буржуазии, а затем и пролетариата, пережила ряд революций, но, прежде чем погибнуть, создала два основанных на возвращении к ценностным принципам традиционной культуры варианта культуры креативной - эпоху собственного утверждения - Классицизма и Барокко и эпоху собственной критики и распада Просвещения.

Эти эпохи представляют собой первую версию тоталитарной культуры. Так мы называем традиционализированную с помощью насилия государственной или церковной власти креативную культуру. Эта культура по форме традиционная, в ней утверждаются ценности социума (сословия, класса, нации, религиозного сообщества, партии), традиций, веры (не обязательно религиозной, но всегда утверждающей ценность идеального прошлого или будущего - коммунистического или райского), однако ее носители представляют собой людей, знакомых с достижениями креативной культуры и, конечно, не чуждых ее ценностей. Тоталитарная культура возникла в результате слишком быстрого становления креативной, вызвавшего разочарование в ней и ностальгию по прошлому, которое еще не утратило своей власти, даже на уровне политических институтов. Тоталитаризм всегда сопровождал становление креативной культуры, будь то в Западной Европе - феодальный абсолютизм, фашизм, будь то в России или в Китае - коммунизм или в Исламском мире - фундаментализм.

Эпоха Просвещения представляет собой первый опыт кризиса тоталитаризма и его отмены, однако ее результаты также не вызвали оптимизма, ибо основные ценности креативной культуры не были в ее условиях реализованы, хотя основные ценности традиционной культуры были 
уже утрачены. Возникла эпоха массового разочарования - эпоха Романтизма. Однако работа по утверждению ценностей креативной культуры продолжалась и завершилась в эпоху Позитивизма - период возникновения демократического общества массового благосостояния. Это общество оказалось возможным благодаря изобретению новых источников энергии - сначала тепла, затем электричества и атома, заменивших механический и малоэффективный труд рабочих на автоматизированный труд инженеров.

Эпоха Модернизма представляет собой период нового и самого радикального кризиса только что окончательно утвердившихся ценностей креативной культуры. Кризис переживают все ее ценности. Кризис ценности творчества выражается в возникновении обезличенной массовой субкультуры, основанной на стереотипном воспроизведении артефактов, подчиняющемся законам рынка и моды, а также в возникновении элитарной субкультуры, основанной на стремлении к протестному усложнению своих артефактов, их эпатирующей оригинальности ради оригинальности. Кризис ценности личности выражается в ее тотальном одиночестве, распаде всех социальных институтов и замене их различными формами социального нарциссизма, группового противостояния, самоутверждения отдельных лиц за счет прав большинства, в ее массовизации, в тоталитаризме, попрании элементарных прав человека, терроризме. Кризис рациональности выражается в том же тоталитаризме, угрозе техногенных и ядерных катастроф, глобальных войн и террористических акций, демографических и экологических трагедий. Эпоха Постмодернизма намечает пути выхода из этого кризиса, утверждая права всех на все, синтезируя различные традиции, индивидуализируя культуру, однако подлинного разрешения кризиса она пока не находит.

\section{СПИСОК ЛИТЕРАТУРЫ}

1. Белл Д. Грядущее постиндустриальное общество. Опыт социального прогнозирования. M.: Academia, 2004.

2. Вебер М. Избранное. Протестантская этика и дух капитализма. М.: Центр гуманитарных инициатив, 2016.

3. Вернадский В.И. Философские мысли натуралиста. М.: Наука, 1988.

4. Маркс К. К критике политической экономии. Предисловие // К. Маркс, Ф. Энгельс. Собрание сочинений в 39 т. Т. 13. М.: Политиздат, 1959. С. 5-9.

5. Риккерт Г. Философия жизни. Киев: Ника-Центр, 1998.

6. Childe, G.V., 2003. Man makes himself. Nottingham: Spokesman Books.

\section{REFERENCES}

1. Bell, D., 2004. Gryadushchee postindustrialnoe obshhestvo. Opyt sotsialnogo prognozirovaniya [The coming of post-industrial society: a venture in social forecasting]. Moskva: Academia. (in Russ.)

2. Weber, M., 2016. Izbrannoe. Protestantskaya etika i dukh kapitalizma [Selected works. The protestant ethic and the spirit of capitalism]. Moskva: Tsentr gumanitarnykh initsiativ. (in Russ.)

3. Vernadsky, V.I., 1988. Filosofskie mysli naturalista [Philosophical thoughts of a naturalist]. Moskva: Nauka. (in Russ.)

4. Marx, K., 1959. K kritike politicheskoi ekonomii. Predislovie [Introduction to the Critique of political economy,]. In: Marx, K. and Engels, F., 1959. Sobranie sochinenii v 39 t. T. 13. Moskva: Politizdat, pp. 5-9. (in Russ.)

5. Rickert, H., 1998. Filosofiya zhizni [Philosophy of life]. Kiev: Nika-Tsentr. (in Russ.)

6. Childe, G.V., 2003. Man makes himself. Nottingham: Spokesman Books.

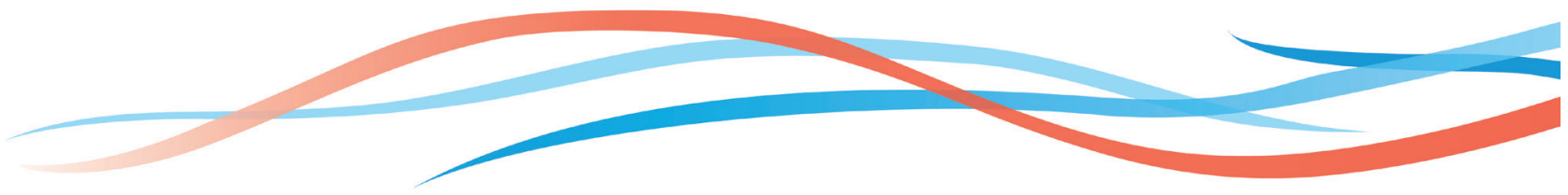

